\title{
Oral acantholytic squamous cell carcinoma shares clinical and histological features with angiosarcoma
}

\author{
Oliver Driemel ${ }^{1}$, Urs DA Müller-Richter*2, Samer G Hakim³, Richard Bauer ${ }^{1}$, \\ Alexander Berndt ${ }^{4}$, Johannes Kleinheinz ${ }^{5}$, Torsten E Reichert ${ }^{1}$ and \\ Hartwig Kosmehl ${ }^{6}$
}

\begin{abstract}
Address: ${ }^{1}$ Department of Oral and Maxillofacial Surgery, University of Regensburg, Franz-Josef-Strauss-Allee 11, 93053, Regensburg, Germany, ${ }^{2}$ Department of Oral and Maxillofacial Plastic Surgery, University of Würzburg, Pleicherwall 2, 97070, Würzburg, Germany, ${ }^{3}$ Department of Maxillofacial Surgery, University Medical Center Schleswig-Holstein, Campus Lübeck, Ratzeburger Allee 160, 23538, Lübeck, Germany, ${ }^{4}$ Department of Pathology, University of Jena, Ziegelmühlenweg 1, 07740, Jena, Germany, ${ }^{5}$ Department of Maxillofacial Surgery, University of Münster, Waldeyerstraße 30, 48149, Münster, Germany and 'Institute of Pathology, HELIOS Hospital Erfurt, Nordhäuser Strasse 74, 99089, Erfurt, Germany

Email: Oliver Driemel - oliver.driemel@klinik.uni-regensburg.de; Urs DA Müller-Richter* - mueller_u2@klinik.uni-wuerzburg.de; Samer G Hakim - samer.hakim@mkg-chir.mu-luebeck.de; Richard Bauer - richard.bauer@klinik.uni-regensburg.de; Alexander Berndt - alexander.berndt@med.uni-jena.de; Johannes Kleinheinz - joklein@uni-muenster.de;

Torsten E Reichert - torsten.reichert@klinik.uni-regensburg.de; Hartwig Kosmehl - hartwig.kosmehl@helios-kliniken.de

* Corresponding author
\end{abstract}

Published: 31 July 2008

Head \& Face Medicine 2008, 4:17 doi:10.1186/1746-160X-4-17

This article is available from: http://www.head-face-med.com/content/4/I/I7

(C) 2008 Driemel et al; licensee BioMed Central Ltd.

This is an Open Access article distributed under the terms of the Creative Commons Attribution License (http://creativecommons.org/licenses/by/2.0), which permits unrestricted use, distribution, and reproduction in any medium, provided the original work is properly cited.
Received: 6 May 2008

Accepted: 31 July 2008

\begin{abstract}
Background: acantholytic squamous cell carcinomas (ASCC) and intraoral angiosarcoma share similar histopathological features. Aim of this study was to find marker for a clear distinction.

Methods: Four oral acantholytic squamous cell carcinomas and one intraoral angiosarcoma are used to compare the eruptive intraoral growth-pattern, age-peak, unfavourable prognosis and slitlike intratumorous spaces in common histological staining as identical clinical and histopathological features. Immunohistochemical staining for pancytokeratin, cytokeratin, collagen type IV, $\gamma 2$-chain of laminin-5, endothelial differentiation marker CD3I and CD34, F VIII-associated antigen, Ki 67antigen, $\beta$-catenin, E-cadherin, $\alpha$-smooth-muscle-actin and Fli-I were done.

Results: Cytokeratin-immunoreactive cells can be identified in both lesions. The large vascularization of ASCC complicates the interpretation of vascular differential markers being characteristic for angiosarcoma. Loss of cell-cell-adhesion, monitored by loss of E-cadherin and $\beta$ catenin membrane-staining, are indetified as reasons for massive expression of invasion-factor In-5 in ASCC and considered responsible for unfavourable prognosis of ASCC. Expression of Fli-I in angiosarcoma and cellular immunoreaction for $\ln -5$ in ASCC are worked out as distinguishing features of both entities.
\end{abstract}

Conclusion: Fli-I in angiosarcoma and In-5 in ASCC are distinguishing features. 


\section{Background}

Both oral angiosarcoma and oral acantholytic squamous cell carcinoma (ASCC) are well-defined entities. The WHO classification of tumours describes angiosarcoma as a malignant tumour consisting of cells recapitulating variably the morphological and functional features of normal endothelium, ICD-O code 9120/3 [1-3]. ASCC (synonyms: acantholytic squamous cell carcinoma, adenoid squamous carcinoma, pseudoglandular squamous cell carcinoma, squamous cell carcinoma with glandlike (adenoid) features, angiosarcoma-like squamous cell carcinoma, adenoacanthoma, pseudovascular adenoid squamous cell carcinoma, pseudoangiosarcomatous carcinoma) is characterized as a squamous cell carcinoma containing pseudo-glandular spaces or lumina, ICD-O code $8075 / 3[4,5]$.

Although angiosarcoma (malignant soft tissue tumour) and ASCC present conceptually complete different tumour entities their histological features are similar and defined by intratumorous spaces. Interestingly both tumour entities show comparable clinical appearance in the oral cavity. The peak incidence of angiosarcoma is the $7^{\text {th }}$ decade [6] and the peak incidence of the oral ASCC is the $6^{\text {th }}$ decade [7]. Macroscopically both entities express in oral cavity fast growing, eruptive lesions and have poor prognosis $[8,9]$. Like all oral squamous cell carcinomas ASCC show male predilection of 1 to 3.5 whereas no sex predilection of oral angiosarcoma is known.

Common and different aspects of oral angiosarcoma and ASCC will be worked out for the correct differential diagnosis. The cellbiological background explaining the peculiar pseudovascular appearance of ASCC is elucidated.

\section{Methods}

\section{Clinical features}

A 63-year-old male patient presented with a polypous, superficial ulcerated, $1.5 \times 1 \times 1 \mathrm{~cm}^{3}$ large mass at the alveolar ridge. A biopsy was taken and the histological diagnosis of an angiosarcoma was established. Metastases developed in pleurae (cytologically verified) and ileum one month after diagnosis of the primary oral lesion. Although an ileum segment resection was carried out the

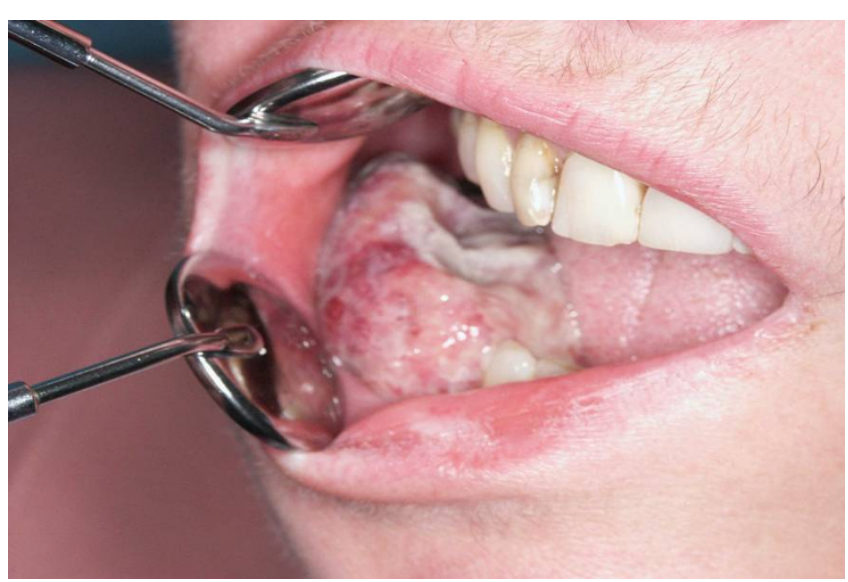

Figure I

Exophytic growth of an oral acantholytic squamous cell carcinoma on the alveolar ridge of the lower jaw.

patient died of angiosarcoma induced intestinal bleeding two months after initial diagnosis.

The clinical data of the ASCC are summarized in table 1.

With the exception of case 3 which represents a metachronical ASCC after multimodal therapy of a hypopharyngeal squamous cell carcinoma all ASCC were diagnosed in an advanced stage. Case 1 developed regional lymph node and distant metastases during adjuvant radiotherapy (Figure. 1).

\section{Methods}

For comparative analysis the tissue of the diagnostic tumour biopsies was fixed in $4.0 \%$ buffered formalin and embedded in paraffin. The slides were stained with $\mathrm{H} \& \mathrm{E}$, PAS, Goldner's trichrome staining and Gömöri.

\section{Immunohistochemistry}

Primary antibodies applied in the study: pancytokeratin (clones AE1/AE3, Dako, Denmark) dilution 1:20, cytokeratin (clone MNF-116, Dako, Denmark) dilution 1:200, collagen type IV (clone C22, Dako, Denmark) dilution $1: 200, \gamma 2$-chain of laminin-5 (clone D4B5, Chemicon, USA) dilution 1:10000, endothelial differentiation marker CD31 (clone JC/70A, Dako, Denmark) dilution

Table I: Clinical features of patients with acantholytic squamous cell carcinoma (ASCC).

\begin{tabular}{|c|c|c|c|c|}
\hline Case & Age & Gender & Site & TNM \\
\hline I & 58 & $f$ & $\begin{array}{c}\text { right alveolar ridge of the } \\
\text { lower jaw }\end{array}$ & pT4 pN0 cM0 LI VI \\
\hline 2 & 57 & $\mathrm{~m}$ & right border of the tongue & cT4 \\
\hline 3 & 68 & $\mathrm{~m}$ & tongue & $\mathrm{cTI}$ \\
\hline 4 & 50 & $\mathrm{~m}$ & floor of the mouth & pT4a pNI cMO LI V0 \\
\hline
\end{tabular}

f: female, m: male 


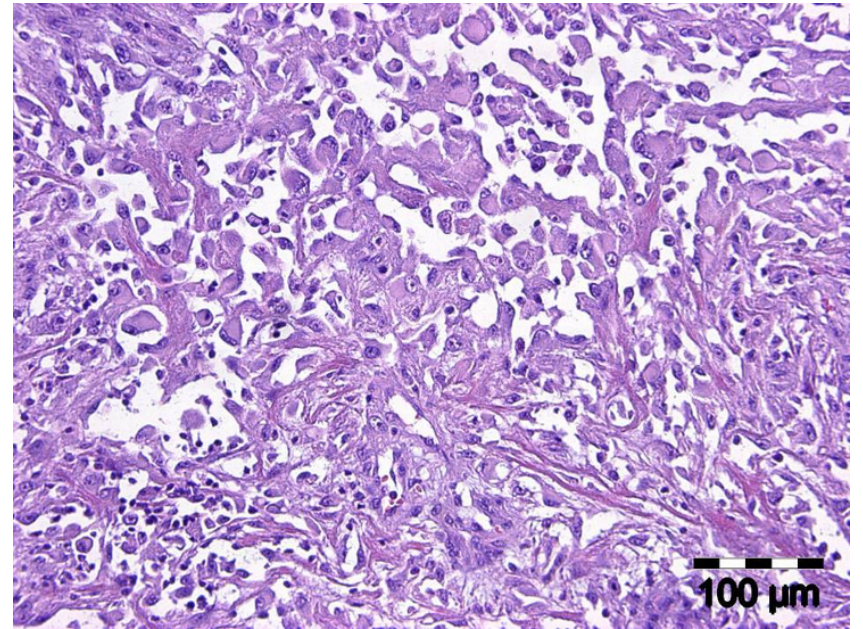

Figure 2

Oral acantholytic squamous cell carcinoma: capillary and papillary growth pattern (H\&E, x I50).

1:100, CD34 (clone QBEND 10, Immunotech, France) dilution 1:500, F VIII-associated antigen (clone F 8/86, Dako, Denmark) dilution 1:200, Ki 67-antigen (clone MIB-1, Dako, Denmark) dilution 1:1000, $\beta$-catenin (clone 17 C 2, Novacastra, U.K.) 1:200, E-cadherin (clone 4A2C7, Zymed, USA) dilution 1:75, $\alpha$-smooth-muscleactin (clone 1A4, Dako, Denmark) dilution 1:400, Fli-1 (polyklonal, Zymed, USA). Primary antibodies were detected using the streptavidin-biotin-alkaline phosphatase-technique (ChemMate, Dako, Denmark). The immunohistochemical procedure was carried out at autostainer plus according to the manufactures' protocol (Dako, Denmark).

\section{Results \\ Histopathologic findings}

The diagnostic biopsies of both entities showed a superficial necrotic zone due to ulceration. The tumour cells were large and showed a polygonal to epitheloid shape. There was a highly pathologic nucleus-cytoplasm-ratio. Prominent nucleoli were a continuous feature. The tumour cells of both entities contained a fine granular PAS-positive material within the cytoplasm. Both lesions were characterized by slit-like intratumorous spaces or papillary and pseudopapillary projections (Figure. 2). In case 3, additionally to the slit-like tumourous spaces a venular- or glandular-like pattern was formed (Figure. 3). The Gömöri staining revealed a discontinuous staining in the basement membrane region at the tumour cell stroma interface. In more solid tumour areas the Gömöri staining demonstrated an acinar or trabecular growth pattern. A dysplastic covering oral mucosa could not be evidenced due to ulceration. Only in one ASCC, dyskeratosis could

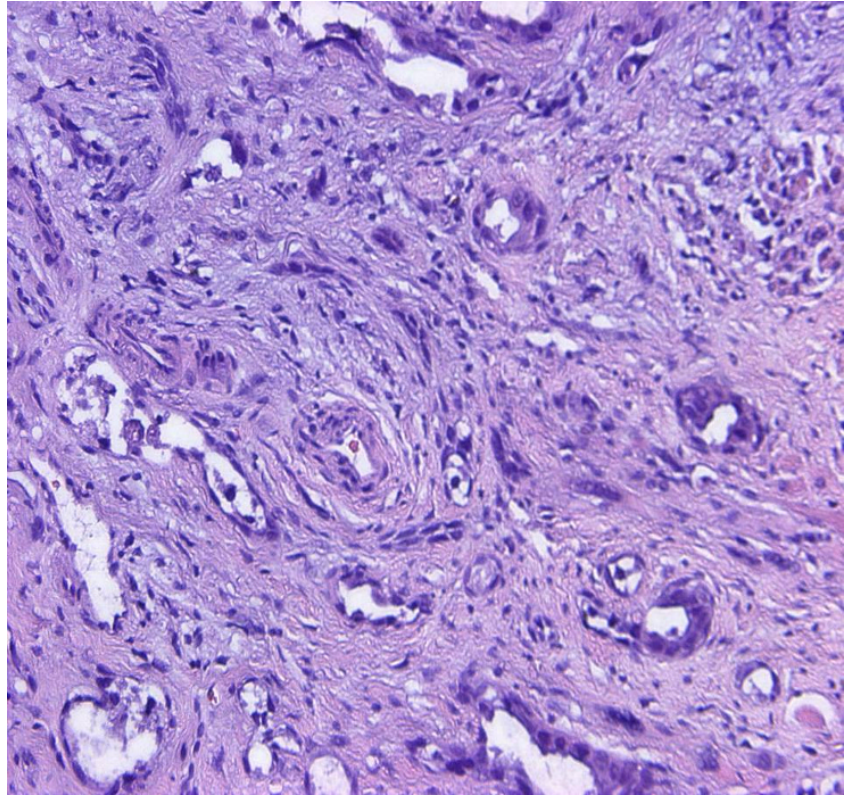

Figure 3

Oral acantholytic squamous cell carcinoma: venularl glandular-like pattern $(H \& E, \times \mid 50)$.

be evidenced in serial sections. Hemorrhagic areas were found in angiosarcoma as well as in ASCC.

\section{Immunohistochemical findings}

Cytokeratin-positive tumour cells were recognized in both angiosarcoma as well as in the four ASCCs. The number of cytokeratin-positive tumour cells in angiosarcoma was lower than in ASCC (Figure. 4).

Ln-5-positive basement membrane region was also found in both entities. In angiosarcoma the ln-5 immunostaining of the basement membrane was regularly localized in tumour sections beneath preexisting epithelial structures. A cellular immunostaining of laminin- 5 was restricted to all four ASCCs (Figure. 5). Around the slit-like intratumorous spaces a discontinuous basement membrane immunostaining was demonstrated in both entities. Moreover, in association to spindle-shaped cells between the spaces a dot-like or membranous immunostaining was visualized using antibodies against collagen type IV.

In the stroma of both entities as well as around the slit-like intratumorous spaces $\alpha$-smooth-muscle-positive cells were diagnosed and often a distinction between stroma myofibroblasts or pericytes could not be made.

CD 31, CD 34 and factor VIII-associated antigen could be found in the majority of the cells of angiosarcoma (Figure. 6). The endothelial differential markers have to be interpreted carefully, because in angiosarcoma not all tumour 


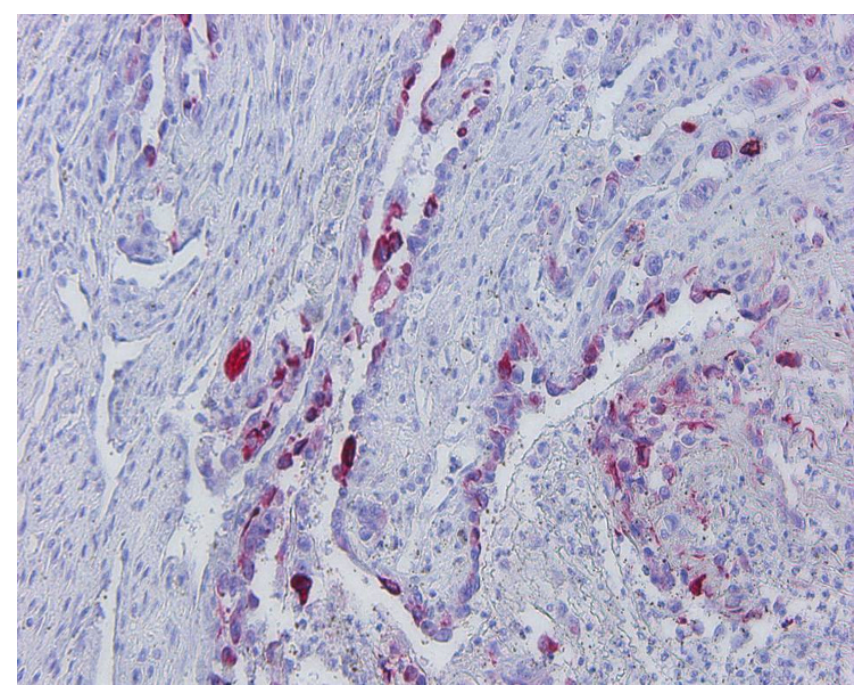

\section{Figure 4}

Oral angiosarcoma: immunohistochemical demonstration of the epithelial intermediate filament protein cytokeratin in a subset of the tumour cells (clones AEI/AE3 $\times$ I50).

cells are stained immunohistochemically positive and in ASCC a large vascularization characterized by positive endothelial differential markers is regularly observed.

The proliferative activity did not discriminate angiosarcoma from ASCC. The Ki 67-index reached 20\%.

Fli-1 immunoreactivity was only recognized in angiosarcoma (Figure. 7).

E-cadherin and $\beta$-catenin were found in all four ASCCs but not in the angiosarcoma. In the majority of the tumour cells there was an E-cadherin immunostaining in cytoplasm and not at the cell membrane. Sometimes $\beta$ catenin was seen not only in the cytoplasm but also within the nucleus.

\section{Discussion}

Several authors have already emphasized the histopathologic similarity of ASCC and angiosarcoma. [10-13]. Although the WHO defines ASCC as an original entity for a long time $[4,5]$, there are less than thirty cases of ASCCs documented in the international literature so far [7]. Both entities may have an association to previous exposal to ionizing radiation $[9,14]$. To determine differential diagnosis and to differentiate ASCC from angiosarcoma an immunohistochemical typing is required regularly, because the epidermoid differentiation may be extremely masked by pseudovascular proliferation. Dyskeratoses may represent a rare pattern in ASCC. The immunohistochemical analysis has to consider on the one side that in

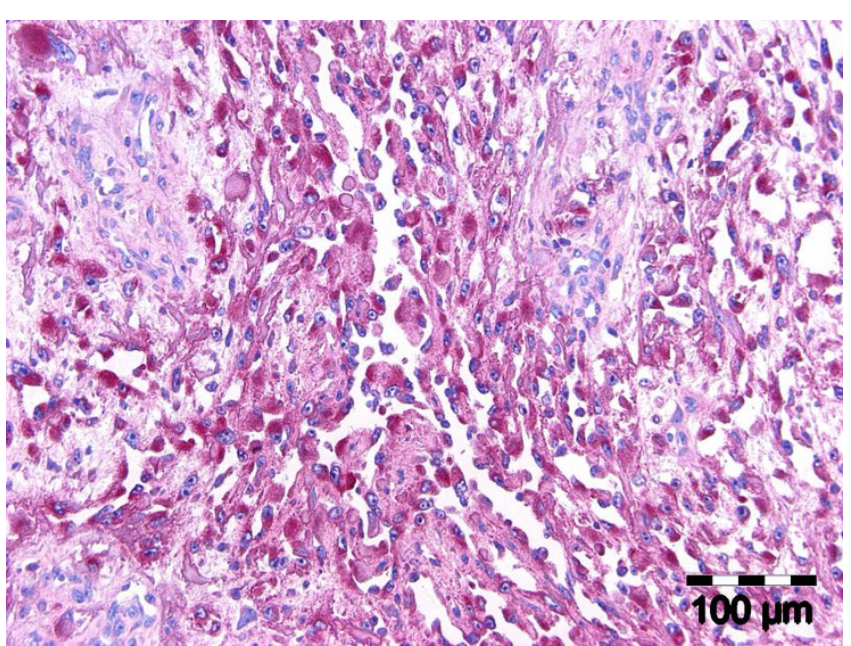

\section{Figure 5}

Oral acantholytic squamous cell carcinoma: immunohistochemical demonstration of the In-5- $\gamma 2$-chain. Note the strong immunostaining within the cytoplasm of the majority of the carcinoma cells (clone D4B5, $\times 150$ ).

soft tissue tumour angiosarcoma cytokeratin-positive cells may appear and on the other side that the plentiful vessels in the tumour stroma of ASCC are signed by endoepithelial differential markers, so that the classic discriminating differential markers cytokeratin, factor VIII-associated antigen and others are often difficult to be interpreted. [15-17]. The Fli-1-protein, a member of the ETS family of DNA-binding transcription factors was recently highlighted as a new vascular differentiation marker $[18,19]$. Although Fli-1 can be also rarely identified in carcinomas [20], ASCC is immunonegative for this marker, so that Fli1 can be recommended to discriminate between Angiosarcoma and ASCC.

The incomplete border of pericytes represents an accepted feature for identifying differentiation disturbed neoplastic vessels of angiosarcoma. The pericytes are emphasized by $\alpha$-smooth-muscle-actin [6]. However the incomplete border of pericytes in structures of angiosarcoma is not suitable for discriminating angiosarcoma versus ASCC, because in ASCC $\alpha$-smooth-muscle-stromamyofibroblasts may mimic the pattern of pericytes lining discontinuously the slit-like tumour-spaces.

Interestingly in angiosarcoma $\ln -5$ positive basal membranes were recognised. Ln-5 is a characteristic protein of epithelial basal membranes that is regularly identified in oral mucosa and in oral squamous cell carinoma [21]. It connects the basal membrane with the hemidesmosomes of epithelial cells and has not been described in mesenchymal basal membranes so far. Because in angiosarcoma in contrast to ASCC no cytoplasmatic marking as a sign of 


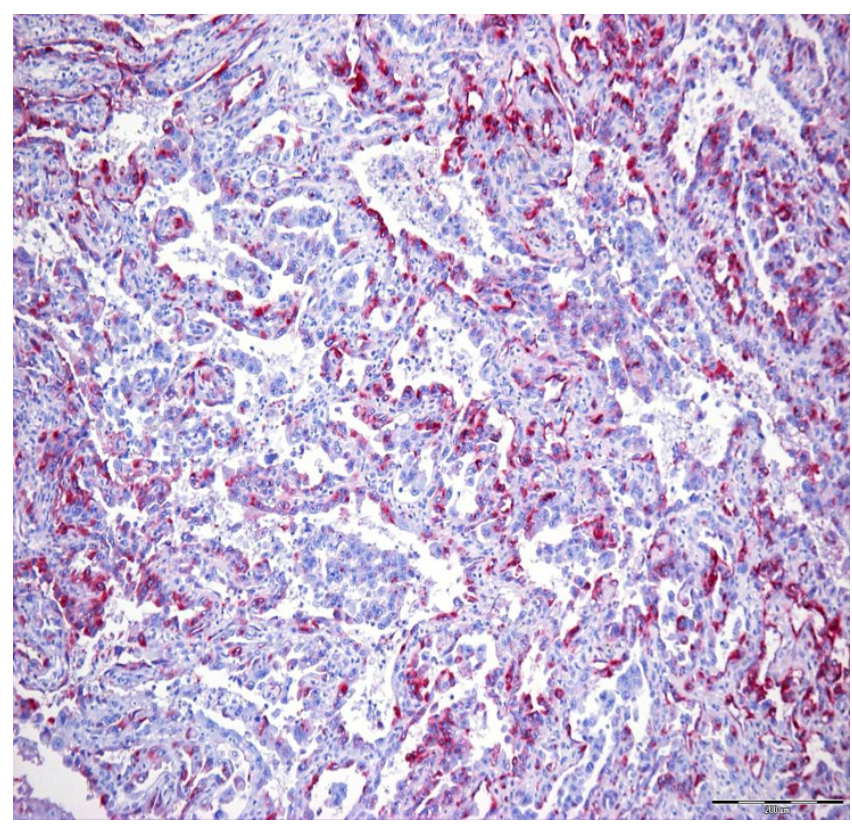

Figure 6

Oral angiosarcoma: immunohistochemical demonstration of factor VIII-related antigen in a subset of the tumour cells lining the vascular spaces $(x \mid 50)$.

synthesis of $\ln -5$ - $\gamma 2$-chain could be made out and because ln-5 was only identified in parts of angiosarcoma localized next to preexisting oral epithelia, it is suggested, that ln-5 of the new formed basal membranes of angiosarcoma comes from the neighbouring preexisting epithelial structures and has only been integrated into the new formed basal membranes of angiosarcoma.

The cytoplasmatic ln-5 detection of ASCC cells presents on the one hand a distinguishing feature between ASCC and angiosarcoma and on the other hand a tumour biological indicator of the unfavourable prognosis of ASCC.

An abundant detection of $\gamma 2$-chain of $\ln -5$ in carcinoma cells is correspondingly accepted in literature as an unfavourable prognostic pattern. The extracellular matrix protein stimulates invasion of carcinoma cells [22-24]. Hlubek and co-workers identified $2001 \beta$-catenin as a transcription-factor of laminin- $\gamma 2$-chain [25]. The membrane-localized $\beta$-catenin-E-cadherin-complex mediates the cell-cell-adhesion, that is obviously disturbed in ASCC and that is responsible for forming of the typical intercellular spaces $[13,26,27]$. In case of a disturbed forming of $\beta$-catenin-E-cadherin-complex at the carcinoma cell membrane $\beta$-catenin liberated from cell membrane is able to migrate into the cell nucleus, to act as a transcription-factor and to induce an overexpression of invasion-factor laminin- $\gamma 2$-chain in ASCC.

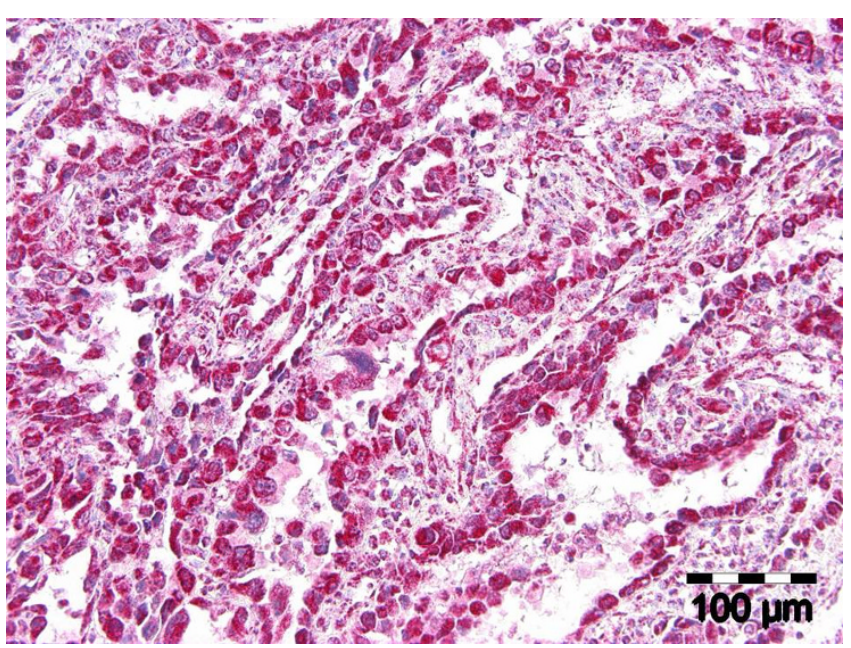

\section{Figure 7}

Oral angiosarcoma: immunohistochemical demonstration of Fli-I in a subset of the tumour cells ( $\times \mid 50)$.

The reduced cell-cell-adhesion and the extremely increased expression of laminin- $\gamma 2$-chain are suggested as cell biological reasons for the extreme early distant metastasising of ASCC during therapy.

In summary angiosarcoma and ASCC do not only share identical clinical features and a similar histopathological pattern in common histological staining but also show overlaps of cytokeratin-expression and of expression of vascular differential markers. Expression of Fli-1 in angiosarcoma and cytoplasmatic immunoreaction for $\gamma 2$ chain of ln-5 in ASCC are worked out as distinguishing features of both entities.

\section{Conflict of interests}

The authors declare that they have no competing interests.

\section{Authors' contributions}

OD acquisition of patients and study design, UMR study design, manuscript drafting, SGH acquisition of patients, RB immunostaining, AB study design, JK review and study design, TR study design, HK immunostaining, histopathological analysis.

\section{Acknowledgements}

This study was supported by grants from the European Union FP6, LSHCCT-2003-5032, STROMA, this publication reflects only the authors' view. The European Commission is not liable for any use that may be made of the information contained.

\section{References}

I. Thompson LDR, Fanburg-Smith JC: Malignant soft tissue tumours. Angiosarcoma. In World Health Organization Classification of Tumours. Pathology and Genetics of Head and Neck Tumours Edited by: Barnes L, Eveson JW, Reichart P, Sidransky D. IARC Press, Lyon; 2005:40-4I. 
2. Thompson LDR, Fanburg-Smith JC: Malignant soft tissue tumours. Angiosarcoma. In World Health Organization Classification of Tumours. Pathology and Genetics of Head and Neck Tumours Edited by: Barnes L, Eveson JW, Reichart P, Sidransky D. IARC Press, Lyon; 2005: I 48-I 49.

3. Weiss SW, Lasota J, Miettinen MM: Angiosarcoma of soft tissue. In World Health Organization Classification of tumours. Pathology and genetics of tumours of soft tissue and bone Edited by: Fletcher CDM, Unni KK, Mertens F. IARC Press, Lyon; 2002: I75-I77.

4. Cardesa A, Zidar N, Alos L: Acantholytic squamous cell carcinoma. In World Health Organization Classification of Tumours. Pathology and Genetics of Head and Neck Tumours Edited by: Barnes L, Eveson JW, Reichart P, Sidransky D. IARC Press, Lyon; 2005:I29.

5. Pindborg JJ, Reichart PA, Smith CJ, van der Waal I: Adenoid squamous cell carcinoma. In WHO histological typing of cancer and precancer of the oral mucosa 2nd edition. Edited by: Pindborg JJ, Reichart PA, Smith CJ, van der Waal I. Springer, Berlin Heidelberg New York; 1997:I5.

6. Meis-Kindblom JM, Kindblom LG: Angiosarcoma of soft tissue: a study of 80 cases. Am J Surg Pathol 1998, 22:683-697.

7. Driemel O, Braxein K, Pistner H, Kosmehl H: Orales AdenoidSquamöses Karzinom. Tumormarker und Prognose, Mund Kiefer Gesichtschir 2004, 8: I 18-122.

8. Batsakis JG, Huser J: Squamous carcinomas with glandlike (adenoid) features. Ann Otol Rhinol Laryngol 1990, 99:87-88.

9. Cawson RA, Binnie WH, Speight PM, Barrett AW, Wright JM: Uncommon type of carcinoma. In Lucas's pathology of tumors of the oral tissues 5 th edition. Edited by: Cawson RA, Binnie WH, Speight PM, Barrett AW, Wright JM. Churchill Livingstone, London; 1998:24I-248.

10. Banerjee SS, Eyden BP, Wells S, McWilliam LJ, Harris M: Pseudoangiosarcomatous carcinoma: a clinicopathological study of seven cases. Histopathology 1992, 21 (1):। 3-23.

II. Horie $Y$, Kato M: Pseudovascular squamous cell carcinoma of the uterine cervical lesion that may simulate an angiosarcoma. Pathol Int 1999, 49:170-174.

12. Nappi O, Swanson PE, Wick MR: Pseudovascular squamous cell carcinoma of the lung: clinicopathologic study of three cases and comparison with the pleuropulmonary angiosarcoma. Hum Pathol 1994, 25:373-378.

13. Zidar N, Gale N, Zupevc A, Dovsak D: Pseudovascular adenoid squamous-cell carcinoma of the oral cavity - a report of two cases. J Clin Pathol 2006, 59: I 206-I 208.

14. Grady AM, Krishnan V, Cohen L: Postirradiation angiosarcoma of the head and neck: report of a case. J Oral Maxillofac Surg 2002, 60:828-83I.

15. Allison KH, Yoder BJ, Bronner MP, Goldblum JR, Rubin BP: Angiosarcoma involving the gastrointestinal tract: a series of primary and metastatic cases. Am J Surg Pathol 2004, 28:298-307.

16. Gagner JP, Yim JH, Yang GC: Fine-needle aspiration cytology of epithelioid angiosarcoma: A diagnostic dilemma. Diagn Cytopathol 2005, 33:429-433.

17. Hufnagel TJ, Kim JH, True LD, Mannelidis EE: Immunohistochemistry of capillary hemangioblastoma. Immuno-peroxidaselabeled antibody staining resolves the differential diagnosis with metastatic renal cell carcinoma, but does not explain the histogenesis of the capillary hemangioblastoma. Am J Surg Pathol 1989, 13:207-216.

18. Billings SD, Folpe AL, Weiss SW: Epitheloid sarcoma-like hemangioendothelioma. Am J Surg Pathol 2003, 27:48-57.

19. Folpe AL, Chand EM, Goldblum JR, Weiss SW: Expression of Fli-I, a nuclear transcription factor, distinguishes vascular neoplasms from potential mimics. Am J Surg Pathol 200I, 25:1061-1066.

20. Rossi S, Orvieto E, Furlanetto A, Laurino L, Ninfo V, Dei Tos AP: Utility of the immunohistochemical detection of FLI-I expression in round cell and vascular neoplasm using a monoclonal antibody. Mod Pathol 2004, 17:547-552.

21. Haas KM, Berndt A, Stiller KJ, Hyckel P, Kosmehl H: A comparative quantitative analysis of laminin-5 in the basement membrane of normal, hyperplastic, and malignant oral mucosa by confocal immunofluorescence imaging. J Histochem Cytochem 200I, 49: I $26|-| 268$.

22. Kosmehl H, Berndt A, Strassburger S, Borsi L, Rouselle P, Mandel U, Hyckel P, Zardi L, Katenkamp D: Distribution of laminin and fibronectin isoforms in oral mucosa and oral squamous cell carcinoma. Br J Cancer 1999, 8 I: I 07I-1079.

23. Patel V, Aldridge K, Ensley JF, Odell E, Boyd A, Jones J, Gutkind J, Yeudall WA: Laminin-gamma2 overexpression in head-and-neck squamous cell carcinoma. Int J Cancer 2002, 99:583-588.

24. Pyke C, Roemer J, Kallunki P, Lund LR, Ralfkiaer E, Danoe K, Tryggvason $\mathrm{K}$ : The $\gamma \mathbf{2}$ chain of kalinin/laminin-5 is preferentially expressed in invading malignant cells in human cancers. Am J Pathol 1994, |45:782-79|.

25. Hlubek F, Jung A, Kotzor N, Kirchner T, Brabletz T: Expression of the invasion factor laminin gamma2 in colorectal carcinomas is regulated by beta-catenin. Cancer Res 200I, 61:8089-8093.

26. Bankfalvi A, Krassort M, Buchwalow IB, Vegh A, Felszeghy E, Piffko J: Gains and losses of adhesion molecules (CD44, E-cadherin, a beta-catenin) during oral carcinogensis and tumour progression. J Pathol 2002, 198:343-35I.

27. Lo Muzio L, Staibano S, Pannone G, Grieco M, Mignogna MD, Certa A, Testa NF, De Rosa G: Beta- and gamma-catenin expression in oral squamous cell carcinomas. Anticancer Res 1999, 19:3817-3826.
Publish with Bio Med Central and every scientist can read your work free of charge

"BioMed Central will be the most significant development for disseminating the results of biomedical research in our lifetime. "

Sir Paul Nurse, Cancer Research UK

Your research papers will be:

- available free of charge to the entire biomedical community

- peer reviewed and published immediately upon acceptance

- cited in PubMed and archived on PubMed Central

- yours - you keep the copyright

Submit your manuscript here:

http://www.biomedcentral.com/info/publishing_adv.asp
BioMedcentral 